\title{
Visually Impaired Students' Creative Thinking in Solving a Geometry Problem
}

\author{
Luthfiana Tarida ${ }^{1,2^{*}}$
}

\author{
${ }^{1}$ Doctoral Program Student of Mathematics Education, Universitas Negeri Surabaya, Indonesia \\ ${ }^{2}$ Nautical Science Program, Akademi Maritim Nusantara Cilacap, Indonesia \\ *Corresponding author.Email: luthfiana.21012@mhs.unesa.ac.id, luthfianatarida@amn.ac.id
}

\begin{abstract}
Every person has an equal opportunity to pursue education, with no exception for visually impaired students. Sometimes, it is difficult for them to learn mathematics, especially geometry. Geometry is usually learned by visual that visually impaired students have limitations due to damaged eyesight. Creative thinking will help visually impaired students to solve this problem. This paper aims to describe visually impaired students' creative thinking in solving geometry problems. The subjects of this research are visually impaired students. This paper is qualitative research with a descriptive exploratory study. The aspects used to know creative thinking are fluency, flexibility, and novelty. Studentsuse creative thinking when solving the problem "Draw a kite with different size of each angle (minimum two kites)!". On the novelty aspect, students can use their problem-solving method using the right process and result. The student can give more than one related idea to solve problems and state it clearly on the fluency aspect. On the flexibility aspect, the student can use a variety of strategies to solve the problems. Students can solve problems mathematical through creative thinking.
\end{abstract}

Keywords: Creative thinking, Visually impaired student, Solving geometry problem, Mathematics.

\section{INTRODUCTION}

Almost all countries apply equal opportunities for every citizen to get an education, including the United State and Indonesia $[1,2]$. The Indonesian Government also provides equal opportunities for visually impaired students [2]. Visually impaired students are students with visual impairments that have an impact on the process of receiving information. This is because the sense of sight is the sense of catching information with the highest proportion, more than $50 \%$. These limitations result in learning differences between visually impaired students and normal students. Visually impaired students learn byutilizing the senses of touch, hearing, smell, and taste. Listening skills are an important basic capital for children with visual impairments. Visually impaired students' listening skills are better than normal students.It doesn't happen automatically but is acquired because of long and systematic practice.

People believe that learners with visual impairment cannot do mathematics, especially geometry. Some of the learners with visual impairment equally think that they cannot cope with the subject.
Geometry is an essential material in learning mathematics because it can be used in the human physical environment [3]. However, many students find it difficult to learn it, because the teacher introduces geometry as abstract material [4]. Students' ability to solve geometric problems can be supported by creative thinking skills, including visually impaired students. Although geometry is synonymous with visual vision, this does not become a barrier for visually impaired students in learning it, if they have creative thinking skills.

[5] found a child with visual impairment with a much better-developed ability to link information. They referred to it as structural priming. The child was able to semantically link information in the process of concept formation and produced divergent and creative thinking, the ability to find multiple solutions to a single problem. They considered this ability to be an important component in creativity and cognitive flexibility [5]. [6] stated that the aspect of creative thinkingis one of the important aspects of $21^{\text {st }}$ century learning. Students can solve various challenging math problems through creative thinking skills. So learning 
mathematics in schools that apply problem-based learning can also improve creative thinking skills. This is because problem-solving does not use routine procedures. Students can explore answers in various ways. Completion of various ways, including indicators in creative thinking.

Creative thinking is a mental activity to find new ideas, find various solutions to a problem. There are three aspects of creative thinking: (a) fluency, the ability of students to provide diverse and correct solutions; (b) flexibility, the ability of students to answer a problem with several different answers; (c) novelty: the ability of students to present a variety of solutions or solutions thatstudents do not usually do at the level of knowledge [3]. The importance of creative thinking skills in solving challenges becomes a guide for writers to explore these abilities from visually impaired students. Thus, visually impaired students have the opportunity to develop their mathematical abilities, especially creative thinking, eventhough they have limited vision. It is hoped that the visually impaired will not prevent the visually impaired student from learning all mathematical theories, including geometry. So, this study aims to describe visually impaired students' creative thinking in solving geometry problems.

\section{LITERATURE REVIEW}

\subsection{Visually Impaired Students}

The World Health Organisation (WHO) defined the word impairment as some abnormal body or mind functions due to genetic factors or environmental factors such as accidents or disease [5]. Visual impairment students in this study refer to children with damage to their visual organs. Visual impairment students learn by non-visual modalities to develop their knowledge [7]. Visually impaired students' ability is no different from normal students. The results of previous studies support this; the students with visual impairment can be passed Polya's phase for solving problems, although there are not perfect [8].

Abraham Nameth also proved the ability and interest of visually impaired students in mathematics. Abraham Nemeth was born blind and later became a renowned scholar of mathematics. He created the Nemeth code forBraille mathematics in America [5].

\subsection{Creative Thinking}

Thinking is the systematic transformation of mental [9]. Creative thinking abilities contain sensitivity and fluency [10]. Torrance defines creative thinking as the ability to sense problems, make guesses, generate new ideas, and communicate results [11].
Several experts have developed instruments to measure mathematical creative thinking skills, such as Balka and Torrance. Balka developed the Creative Ability Mathematical Test (CAMT) instrument, and Torrance developed the Torrance Tests of Creative Thinking (TTCT) instrument [12]. These two instruments are in the form of making math problems based on the information contained in the questions related to the given daily situations. The method or method of measuring the mathematical creative thinkingability used by Balka above is often called the task of problem-posing, problem finding, or production divergent. This test measures three aspects of mathematical creative thinking skills, fluency, flexibility, and novelty. The fluency aspect relates to the number ofrelevant questions. The aspect of flexibility is related to the number of varieties or types of questions. The noveltyaspect relates to the uniqueness or how rare a type of question is.

The aspects of creative thinking are fluency, flexibility, and novelty. Fluency provides more than one idea relevant to solving the problem, and its disclosure is complete and clear. Flexibility, using a variety of strategies and ways to solve problems. Novelty, using his own way of solving problems with the right process and results.

Visually impaired students' creative thinking is generally the same as normal students. Creative thinking in this study was obtained through solving mathematicalproblems that required the emergence of these threeaspects, fluency, flexibility, and novelty.

\section{METHODS}

This paper aims to explore and investigate visually impaired students' creative thinking processes in solving geometry problems. This research adopted an exploration approach to analyze the data by using a qualitative approach [13]. To get these aims, the students were given the task of solving a geometry problem, and then the students were interviewed. The participant is a student in Junior High School, MTs Yaketunis Yogyakarta, Indonesia. To determine the participant, it will be used to modify the test essays of Torrance and Balka. The test contains three aspects of creative thinking skills. The test consists of four questions about triangles andquadrilaterals.

\section{RESULTS}

Before doing the creative thinking test, visually impaired students are given problem-based learning. Problem-based learning, used during the learning process to trigger creative thinking skills of visually impaired students. An example of a Re-discovery activity of the definition of a triangle (Figure 1). 

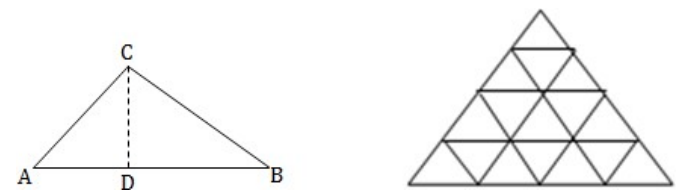

Figure 1 An example of a Re-discovery definition of a triangle.

Figure 1 is converted into braille and tactual images (Figure 2)

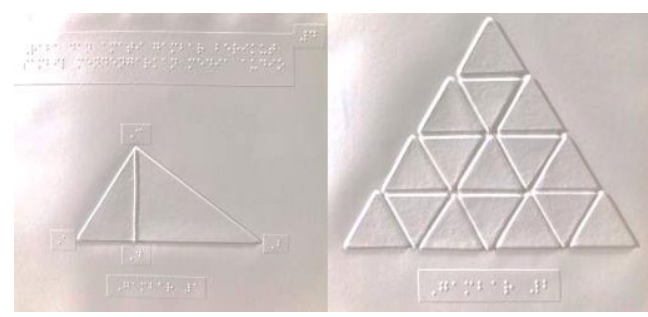

Figure 2 Tactual image of a triangle.

Visually impaired students are assisted with audio media to rediscover the definition of a triangle. The audio media contains sound with the sentence, "To find the meaning of triangle, feel and observe pictures 1 and 2 onpage 15 module then answer the following questions.

1. How many non-linear points are there in triangle $\mathrm{ABC}$ ? Mention!

2. Mention the line, which is the height and base of the triangle. Give your reason!

3. What conclusions can you get about the meaning of atriangle?

4. A triangle is formed from three dots. Is this statementtrue? Give your reasons.

5. Discuss with your friend and determine the number of triangles in Figure 2. You can correct your answer byreading the meaning of the triangle in the module. Seeyou later".

In this process, student $\mathrm{C} 3$ had difficulty in determining the non-linear point on triangle $\mathrm{ABC}$. Student C3 knows there are 3 (three) dots but does not understand whether the 3 (three) dots are in line or not. Student C4 states that a point that is not a line connects two lines. Students are still confused in determining the height and base of a triangle. When the teacher states the concept of perpendicular to the height and base, the students begin to feel the tactual picture of a triangle and mention that $\mathrm{CD}$ is the triangle's height and AB is the triangle's base. It is concluded that the triangle is formed from three points $\mathrm{A}, \mathrm{B}$, and $\mathrm{C}$, which are not in line. Point $\mathrm{A}$ is connected to $\mathrm{B}$. Point $\mathrm{B}$ is connected to point $\mathrm{C}$, and point $\mathrm{C}$ is connected to point $\mathrm{A}$. The line $\mathrm{CD}$ is the triangle's height because it is perpendicular to line $\mathrm{AB}$ as its base.
Learning activities that trigger creative thinking skills are also carried out in rediscovering the concept of the perimeter of a triangle (Figure 3 ).

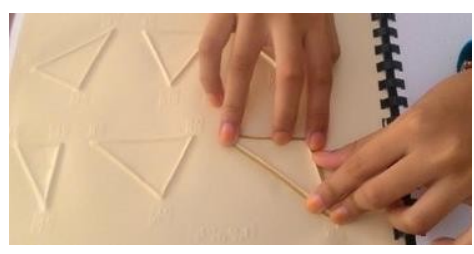

Figure 3 Tactual image perimeter of a triangle.

Students find the concept of the circumference of a triangle using a rope attached to the lines of a triangle, as shown in Figure 3. The problem-solving process encourages students to find concepts and formulas for the perimeter of triangles and quadrilaterals. Based on the discovery process, students have many ways to calculatethe perimeter of triangles and quadrilaterals.

Subsequent learning activities aim for students to be able to (1) find a formula of a triangle, square, rectangle, and parallelogram; (2) solve problems and problems related to the area of triangles, squares, rectangles, and parallelograms; (3) improve the ability to think creatively and independent learning through the process of problem-solving. Students' creative thinking skills can increase because students can find various ways to calculate the area of triangles and quadrilaterals through problem-solving. The activity of discovering how to calculate the area of a triangle and quadrilateral can be seen in Figure 4.

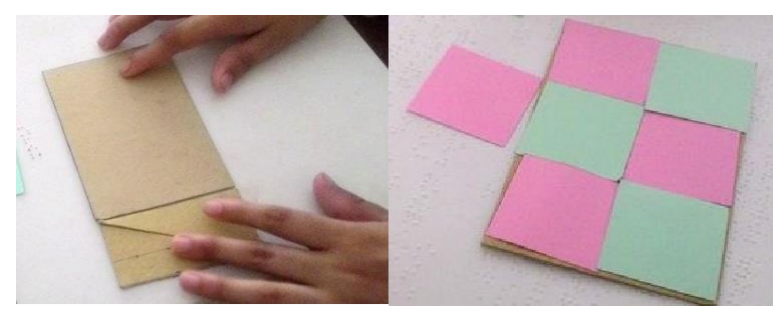

Figure 4 Area of a triangle and quadrilateral.

Based on Figure 4, students can find the area concept of a parallelogram through a rectangular area concept approach. The unit square section serves as the area that covers the parallelogram. The skill of the sense of touch is one of the causes of increasing creative thinking skills. Visually impaired students should often be encouraged to use their sense of touch for cognitive purposes to enrich their cognition.

Visually impaired students are given geometry problems about creative thinking skills, including: "Draw a kite with different sizes of each angle (minimum two kites)!" That problem is an open-ended problem that is arranged based on creative thinking skills. On the novelty aspect, students can solve problems using the right process and result. On fluency aspect, students can give more than one related 
idea to solve problems and state it clearly. On the flexibility aspect, students can provide a variety of interpretations to the picture, stories, or problems. They also can use a variety of strategies to solve the problems. Creative thinking skills are also improved because of the help of visual aids on the problem in finding the concept of formula and area of a quadrilateral.

The next problem is, students are instructed to use at least two ways to determine the area of the shaded area in the $\mathrm{ABCD}$ rectangle (Figure 5).

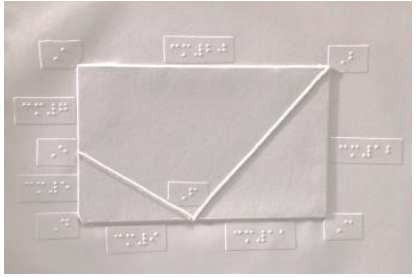

Figure 5 First Problem.

C1 students get a score of 10 out of a maximum score of 14. The student gave an answer that represented the three aspects of creative thinking ability: (1) fluency, gave an idea that was relevant to problem-solving and the disclosure was complete and clear (score 4 out of 6); (2) flexibility, giving answers in more than one way but the results are wrong because there are errors in the calculation process (score 3 out of 4) and (3) novelty, giving answers in their way, the calculation process has been directed but not completed (score 3 of 4 ).

Student C1's answer is with the idea of dividing the area of the shaded area firstly:

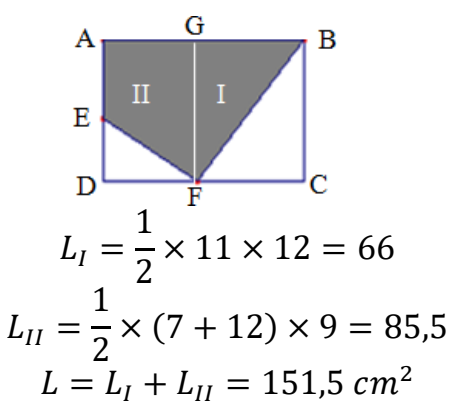

Student $\mathrm{C} 1$ tried to answer in other ways but did notfinish, as follows:

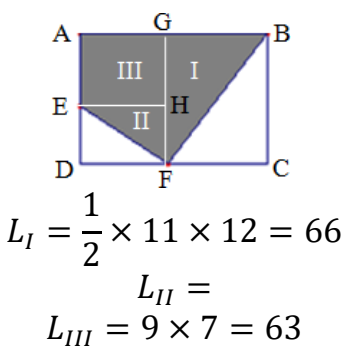

A4 student gets a score of 3 (three). The student has difficulty understanding the location of the shaded area. A4 students are different from other students in the novelty aspect, but the answer is still not correct. The student calculates the area of the unshaded area. Then calculate the area of the rectangle minus the area of the unshaded area!

The next problem determines the area of the trapezoid (Figure 6) in a different way

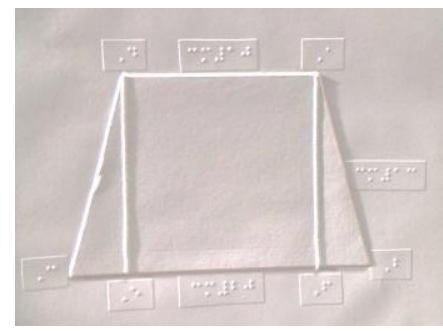

Figure 6 Second Problem.

The highest score was obtained from C4 students, with a score of 7 . A score of 4 on the fluency aspect provides an idea relevant to problem-solving, and the disclosure is complete and clear. Score 2 provides answers in one way, and there are no errors in the calculation process so that the results are correct. Score 1 on the novelty aspect, which is to provide answers in the usual way as follows:

$$
\begin{gathered}
L=\frac{1}{2} \times(10+20) \times t \\
A B=E F=10 \mathrm{~cm} \\
C F+F D=C D-E F=20-10=10 \mathrm{~cm} \\
C F=F D \text { so } C F=F D=\frac{10}{2}=5 \mathrm{~cm} \\
A E=\sqrt{A C^{2}-C E^{2}}=\sqrt{13^{2}-5^{2}}=12 \mathrm{~cm} \\
L=\frac{1}{2} \times(10+20) \times 12=180 \mathrm{~cm}^{2}
\end{gathered}
$$

The next problem in item number 3 is that Rizqi makes an ABCD kite with an area of $240 \mathrm{~cm} 2$. Use more than one way to determine each diagonal's minimum possible prayer length (not a decimal number)!

C1 students get a score of 10 out of a maximum score of 14. The student gave an answer that represented the three aspects of creative thinking ability, namely: (1) fluency: gives more than one relevant idea to determine several possible diagonal lengths of the kite; (2) flexibility: using various strategies and methods from the ideas given to determine several possible diagonal lengths of the kite; (3) novelty: if the ideas and methods used are different from other students.

Student C1 finds the factors of 120, then pair two numbers multiplied by 120 . The answers from A4 students are:

$$
\begin{aligned}
L= & \frac{1}{2} \times d_{1} \times d_{2}=240 \\
& d_{1} \times d_{2}=120
\end{aligned}
$$


Student A4 determines $d 1$ dan $d 2$ by trial and error. Students are only able to try and answer correctly for one answer, as follows:

$$
\begin{gathered}
\text { First Possibility : } \\
\text { for example } d_{1}=20 \mathrm{~cm}, \\
\text { then } d_{2}=240 \div 2 \div d_{1}=120 \div 20=6 \\
\text { Second Possibility : } \\
\text { for example } d_{1}=10 \mathrm{~cm}, \\
\text { then } d_{2}=240 \div 2 \div d_{1}=120 \div 10=12 \\
\text { Third Possibility: } \\
\text { For example } d_{1}=5 \mathrm{~cm}, \\
\text { then } d_{2}=240 \div 2 \div d_{1}=120 \div 5=24
\end{gathered}
$$

Problem number 4 is, make two questions with clear and correct answers about quadrilaterals and or triangles. Use two ways to answer each question that has been made. $\mathrm{C} 4$ students get a score of 8 with the following answers:

Find the perimeter of a rectangle with a length of 6 $\mathrm{cm}$ and a width of $4 \mathrm{~cm}$

$$
\begin{aligned}
& \text { I: } K=p+p+l+l=6+6+4+4=20 \mathrm{~cm} \\
& \text { II: } K=2(p+l)=2(6+4)=20 \mathrm{~cm}
\end{aligned}
$$

C4 students answered with fluency, giving more than one idea for a quadrilateral question, flexibility: using various strategies and methods from the idea of a quadrilateral question and novelty: the ideas and methodsused were different from other students.

Creative thinking skills can improve students' ability to solve mathematical problems. Creative thinking is themost important part of the 4.0 industrial revolution era. Therefore, creative thinking skills must be trained as early as possible, so visually impaired students can compete in industry and society [14]. The challenges of a rapidly changing world require innovative ideas and approaches. The ability to think creatively is certainly needed in facing these challenges.

Learning mathematics in schools for visually impaired students provides very few opportunities for creative thinking skills. Creative thinking skills can improve achievement [15]. This also encourages researchers to develop creative thinking skills so that theycan be improved [16].

Based on the analysis of answers to creative thinking problems, visually impaired students can develop their creative thinking skills even though they are not maximal. This can be used as the basis for supporting visually impaired students to continue to improve their creative thinking skills, for example, through appropriate learning and strategies. Every individual has the same potential in developing creative thinking skills, including visually impaired students [16].

\section{CONCLUSION}

This research concludes that visually impaired students' creative thinking skills can be described by giving geometry problems. The ability to think creativelycan be an alternative solution in overcoming the shortcomings of visually impaired students in solving geometry problems.

Although geometry is a study that requires visual ability, Visually impaired students can solve geometry problems with their creative thinking skills. Students do not have to memorize procedural formulas to solve math problems. Students can even find their way of solving math problems correctly. The ability to think creatively like this is also needed in solving problems in life. With the ability to think creatively, a person can survive and face various challenges in life. Therefore, the education of visually impaired students is recommended to emphasize the ability to think creatively.

\section{AUTHORS' CONTRIBUTIONS}

LT, the author, fully contributed from the beginning to the end of the completion of the research. LT contributed to finding ideas and research objectives and determining the appropriate method to answer the formulation of the problem. LT also conducts theoretical studies, data collection, and analysis to obtain conclusions from this research that follow the objectives.

\section{ACKNOWLEDGMENTS}

The author would like to express their deepest gratitude to the academic community of MTs Yaketunis Yogyakarta where the research is conducted, Universitas Negeri Surabaya and the Akademi Maritim Nusantara Cilacap as the authors' institutions. The authors also thank the Ministry of Education, Culture, Research and Technology (Kemdikbudristek Indonesia), the Indonesia Endowment Fund for Education (LPDP), the Pusat Layanan Pembiayaan Pendidikan (Puslapdik), and the Indonesian Education Scholarships (BPI) for sponsoring funds so that this research can be published.

\section{REFERENCES}

[1] O. G. Klingenberg, A. H. Holkesvik, L. B. Augestad, Digital learning in mathematics for students with severe visual impairment: A systematic review, Br. J. Vis. Impair., 38(1) (2020) 38-57. DOI: https://doi.org/10.1177/0264619619876975.

[2] Undang-Undang Dasar 1945 pasal 31 Ayat 1. Republik Indonesia, Jakarta. URL: https://jdih.kemenkeu.go.id/fulltext/1989/2tahun 1989uupenj.htm 
[3] A. N. Aini, M. Mukhlis, A. M. Annizar, M. H. D. Jakaria, and D. D. Septiadi, Creative thinking level of visual-spatial students on geometry HOTS problems, J. Phys. Conf. Ser., 1465(1) (2020) 1-6. DOI: https://doi.org/10.1088/1742$6596 / 1465 / 1 / 012054$

[4] M. Adusei, Geometry Appcessory for Visually Impaired Children, Design practice research (2017).

URL: https://scholarworks.unist.ac.kr/handle/201301/2 1729.

[5] J. I. Jikukka, Effect applied orientation and mobility programme on attitude and achievement ingeometry of learners with visual impairment in Abuja and Gindiri, Nigeria, A thesis Dep. Spec. Educ. Rehabil. Scineces (2015) 1-116. URL: http://hdl.handle.net/123456789/899

[6] A. Wijaya, Pendidikan Matematika Realistik Indonesia, Yogyakarta: Graha Ilmu, 2012.

[7] D. Abrahamson, V. J. Flood, J. A. Miele, and Y. T. Siu, Enactivism and ethnomethodological conversation analysis as tools for expanding Universal Design for Learning: the case of visually impaired mathematics students, ZDM - Math. Educ. 51(2) (2019) 291-303. DOI: https:/doi.org/10.1007/s11858-018-0998-1.

[8] A. R. Pratama, D. R. S. Saputro, and R. Riyadi, Problem solving of student with visual impairment related to mathematical literacy problem, J. Phys. Conf. Ser. 1008(1) (2018) 1-10. DOI: https://doi.org/10.1088/1742$6596 / 1008 / 1 / 012068$

[9] J. Pretz, M. Habibie, and K. N. Dunbar, The Cambridge Handbook of Thinking and Reasoning Related papers The Cambridge Handbook of Thinking and Reasoning. 2005.

[10] R. Hu, Y. Y. Wu, and C. J. Shieh, Effects of virtual reality integrated creative thinking instruction on students' creative thinking abilities, Eurasia J. Math. Sci. Technol. Educ. 12(3) (2016) 477486.

DOI: https://doi.org/10.12973/eurasia.2016.1226a.

[11] M. N. Anwar and S. Sahibzada, A Comparison of Creative Thinking Abilities of High and Low Achievers Secondary School Students Int. Interdiscip. J. Educ. 1(1) (2012) 846-853. URL: http://iijoe.org/v1/IIJE_04_v1_i1_2012.pdf

[12] E. P. Torrance, Document resume, Pap. prsesnted Annu. Meet. Am. Educ. Res. Assoc 3(7) (1972) $1-42$. URL: https://files.eric.ed.gov/fulltext/ED061544.pdf
[13] A. S, D. Juniati, and T. Y. E. Siswono, Reflective thinking in solving an algebra problem: a case study of field independent-prospective teacher, J. Phys. Conf. Ser. 893 (2017) 1-6. DOI: https://doi.org/10.1088/1742-6596/893/1/012002.

[14] F. Sarnita, A. Fitriani, Widia, Pengembangan Perangkat Pembelajaran Model PBL Berbasis STEM untuk Melatih Keterampilan Berfikir Kreatif Siswa Tuna Netra, J. Pendidik. Mipa, 9(1) (2019) 38-44. DOI: https://doi.org/10.37630/jpm.v9i1.180.

[15] J. K. Teske et al., Teacher-Made Tactile Science Materials with Critical and Creative Thinking Activities for Learners Including Those with Visual Impairments, Online Submission (2014). URL: https://files.eric.ed.gov/fulltext/ED547679.pdf

[16] K. A. Al-Dababneh, M. M. al-Masa'deh, and E. M.Oliemat, The effect of a training programme in creativity on developing the creative abilities among children with visual impairment, Early Child Dev. Care 185(2) (2015) 317-339. DOI: https://doi.org/10.1080/03004430.2014.924113. 